\title{
Risk Assessment System and Model Construction of Characteristic Town Construction
}

\author{
Yingyue Sun, Peng Chen \\ College of Tourism and Geographical Science, Jilin Normal University, Siping 136000, China
}

\section{特色小镇建设风险评价体系与模型构建}

\author{
孙港悦, 陈鹏 \\ 吉林师范大学旅游与地理科学学院, 四平 136000 , 中国
}

\begin{abstract}
The characteristic town is an innovative economic model developed on the basis of China's massive economy and county economy, and it is a new practice of supply side reform. But there are various risks in the process of construction, which directly affect the effect of its construction. On the basis of risk theory, from the perspective of risk characteristics analysis and risk identification, the 5 first grade evaluation factors of land risk, policy risk, capital risk, industry risk and operation risk are selected and 16 two grade evaluation factors are selected, and the evaluation index system and model are constructed, and qualitative factor quantitative treatment method of the risk of the characteristic town construction is discussed. The findings can provide decision-making basis for the sustainable development of the characteristic towns, and provide new research methods and ideas for the risk research of the characteristic towns.
\end{abstract}

Keywords: characteristic town; risk; risk management

摘要

特色小镇是我国在块状经济和县域经 济基础上发展而来的创新经济模式, 是供给 侧改革的新实践。但在建设过程中存在各种
风险, 直接影响其建设的效果。以风险理论 为基础, 从风险特征分析、风险识别角度出 发, 篮选出土地风险、政策风险、资金风险、 产业风险、运营风险 5 个一级评价因子及 16 个二级评价因子, 并构建评价指标体系与模 型, 且讨论了特色小镇建设风险中的定性因 子定量化处理方法。研究结果可为特色小镇 可持续发展提供决策依据, 同时也为特色小 镇风险相关研究提供新的研究方法与思路。 关键词: 特色小镇; 风险; 风险管理

特色小镇是在 2014 年杭州云栖小镇首 次被提及, 之后 2016 年住建部等三部委力 推, 这种在块状经济和县域经济基础上发展 而来的创新经济模式, 是供给侧改革的新实 践, 亦是新的历史时期、新的发展阶段的创 新探索和成功实践 [1]。然而特色小镇快速 建设发展过程呈现出一些问题, 很大程度上 制约了特色小镇的发展。因此, 在特色小镇 建设之前对其进行建设风险评价, 避免盲目 建设, 为特色小镇建设做到有的放矢提供依 据。

国外学者对特色小镇研究开展较早, 分 别从特色小镇建设规模、发展策略、效益等 方面开展了相关研究 [2]。如费莱特曼从特 色小镇人口规模角度出发, 提出了 5 万人口 的农区单位建设目标; Gibson 等提出了为促 进区域经济的发展需要对特色产业升级整 合方法, 并提出发展策略; 克莱尔墨菲等以 旅游特色小镇为案例, 得出经济和社会上取 得了巨大效益; 梅拉妮凯史密斯从旅游、文 
化、休闲融合角度出发, 提出推动特色小镇 的建设方案 [3]。

国内大多数学者多数是以浙江经验为 参照, 对各地特色小镇开展相关研究 [3], 首先是概念上的定义 [4-7], 特色小镇与行 政区和产业园不同，是融合产业、旅游、社 区、文化等多功能的创新创业平台或空间形 态 [8-9]。另一方面, 从特色小镇的形成机 制开展相关研究, 有的学者认为特色小镇是 区域经济的转型工具, 或是在 “一品一镇” 政策上转化而来。还有学者认为特色小镇是 产业园转型升级而来, 或特色小镇是由城镇 化发展到一定时期的必然产物 [10-12]。

通过对国内外相关研究总结发现, 针 对特色小镇相关研究多数集中在概念、形成 机制、发展策略及效益等方面, 上述研究虽 对特色小镇建设起到了一定的作用, 但对于 小镇建设前的风险评价并没有涉及。风险评 价是对特色小镇未来建设过程中可能面临 或潜在的风险加以判断、归类和对风险性质 进行鉴定的过程。因此, 本研究结果可为特 色小镇建设提供决策依据。

\section{1. 特色小镇建设风险识别}

目前我国分两批在 32 个省、市、自治 区等地共建设了 401 个特色小镇 (见图 1), 其分布范围广、类型较多, 在建设过程中受 自身及周边环境的影响较多, 风险类型多种 多样、错综复杂。有潜在的、也有实际存在 的; 有其内部的、也有其外部的。由于风险
是在一定时期和某一特定条件下客观存在 的, 那么其存在的条件是什么, 以及损害发 生可能性有多大等, 都是风险识别过程中予 以解决的问题。因此, 下面将对尚未发生的、 潜在的、客观的各种特色小镇建设过程中的 风险, 进行系统地、连续地进行识别与归类, 并分析产生风险的原因。

\section{1 风险特征}

（1）客观性。风险是客观存在的, 它 是不以人的意志为转移的。且风险是由自然 现象和社会现象所引起的, 甚至可能是自然 界自我平衡的必要条件。自然界的运动是由 其运动规律所决定的, 而这种规律是独立于 人主观意识之外而存在的。人们只能发现、 认识和利用这种规律, 而不能改变之, 因此, 风险是一种客观存在。有的风险是没有办法 回避或是没有办法消除的。

（2）相对性。风险是相对的, 是可以 变化的。风险它不仅跟风险客体, 也就是风 险事件本身所处的时间与环境有关, 而且它 跟风险的主体, 即从事风险活动的人、事、 物有着直接关系。所以, 不同的人、事、物, 由于它自身的条件、能力、环境的不同, 对 同一个风险事件, 可能它的应对方式也不一 样。

(3) 可预测性。风险是一个在特定的 时间与空间条件下发生的, 所以, 它是现实 环境和变动的不确定, 在未来事件当中的一

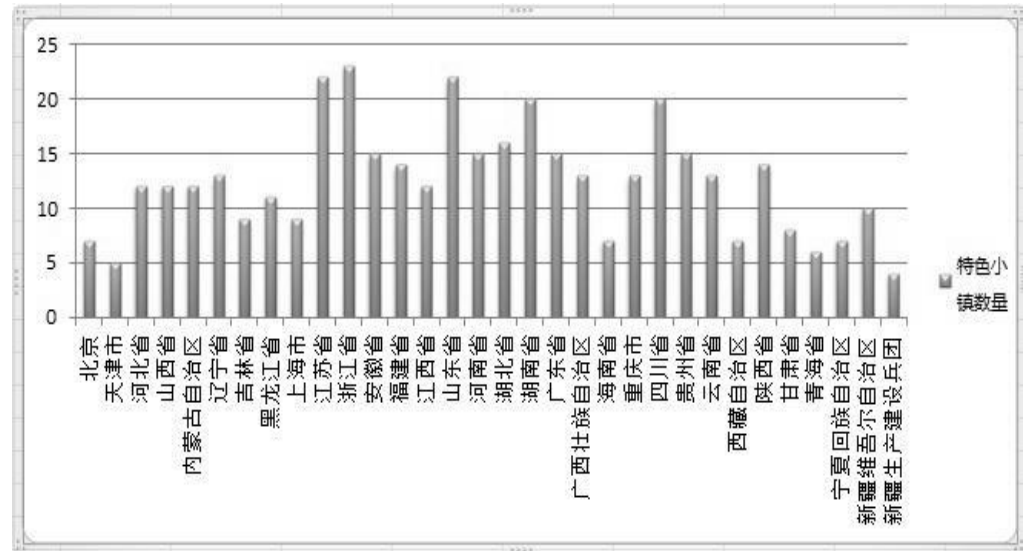

图 1. 我国特色小镇分布情况 
种反映。它可以通过对现实环境因素的观察, 初步可以进行预测, 为减小未来发生的事件 造成的损失提供决策依据。

(4) 风险的可控性。风险是在特定的 条件下, 不确定性的一种表现, 当条件改变 时, 引起风险事件的后果, 可能也会发生改 变。因此, 依据风险的改变条件, 结合预测、 评价等过程, 可以对风险有效的实施控制, 以最大程度的减小损失。

（5）偶然性。从全社会看, 风险事故 的发生是必然的。然而, 对特定的个体来说, 风险事故的发生是偶然的, 这就是风险的偶 然性。这种偶然性表现出种种不确定性: (1) 风险事故发生与否不确定。(2)风险事故何时 发生不确定。(3)风险事故将会怎样发生, 其 损失多大, 也是不确定的。

\section{2 风险识别}

依据风险特征, 结合特色小镇建设政策 及其实际情况, 本文归纳出以下五种风险类 型, 以期为特色小镇建设提供决策依据, 做 到有的放矢。

(1) 土地风险

土地风险主要是由于法律和政策原因 而导致的合同风险及项目地块上存在制约 条件而引起的成本风险, 以及土地性质与用 地需求不匹配带来的开发风险, 此类风险是 导致特色小镇开发早期天折的主要因素。

(2) 政策风险

政策风险是指对特色小镇开发建设提 出的相关标准、规范和要求等政策的不可持 续性, 以及优惠政策不能充分落实, 或者地 方政治生态的不稳定性对特色小镇持续发 展造成的风险。因此, 地方政治生态和政策 的稳定性是吸引特色小镇招商引资的有利 条件。

（3）资金风险

资金风险通常指实际利率、实际回报率 因通货膨胀或其它原因等其他因素造成的 不确定性, 但特色小镇在开发建设过程中, 容易因开发主体缺乏相关投资和运营经验, 而造成投资成本远超预算或因经营不善导 致的现金流短缺等风险。资金是决定特色小 镇是否能够可持续建设的重要条件之一, 因
此, 资金风险的预防是特色小镇建设成功的 关键。

（4）产业风险

产业风险是指特色小镇没有从在地资 源或产业发展优势出发进行精准定位, 会出 现房地产化、产业简单复制等现象, 进而导 致缺乏核心竞争力的风险。特色小镇建设过 程中包括农业、工业、交通运输业等众多行 业, 各产业利益相互联系、具有不同分工, 因此, 支持特色小镇发展过程中不能独自发 展某一行业, 应该围绕主体产业经营对象、 经营范围共同发展及多种产业融合使特色 小镇各产业良性发展。

（5）运营风险

运营风险一方面是由于外部环境的复 杂性和变动性, 如非典、地质灾害等不可抗 力因素而带来的风险; 另一方面是由于内部 主体对环境的认知能力和适应能力的有限 性以及运营团队的不稳定性带来的经营损 失风险。运营是一项系统性的工程, 它要求 相应的政策环境、法律环境、社会环境、市 场环境、人才环境等, 为资本运营的顺利开 展提供服务, 以降低资本运营风险。

\section{2. 风险评价体系构建}

\section{1 体系构建}

评价指标体系是指由表征评价对象各 方面特性及其相互联系的多个指标, 所构成 的具有内在结构的有机整体。各指标间既要 有一定的逻辑关系, 又要从不同侧面反映特 色小镇建设风险评价特点。指标体系构建务 必确保具有一定典型性、代表性, 尽可能的 反映出待评内容, 且指标便于计算。综合上 述特色小镇建设风险评价识别过程, 结合实 际, 综合构建表 1 特色小镇建设风险评价指 标体系, 各指标权重采用层次分析法 (AHP) 计算。

\section{2 风险因子量化}

通过上述特色小镇建设风险评价体系 中的因子可以看出, 各因子均为定性指标, 很难直接量化, 因此本研究中采用实地调查 与专家打分法对各定性指标予以赋值, 赋值 等级划分为三个等级: $1 、 2 、 3$ 分 (见表 2), 
表 1. 特色小镇建设风险评价指标体系及权重

\begin{tabular}{|c|c|c|c|}
\hline & 一级因子 & 二级因子 & 权重 \\
\hline & \multirow[t]{2}{*}{ 土地风险 $(T)$} & $\left(x_{1}\right)$ 合同是否正规 & 0.12 \\
\hline & & $\left(x_{2}\right)$ 土地性质与用地需求是否匹配 & 0.13 \\
\hline 特 & \multirow[t]{3}{*}{ 政策风险（Z） } & （ $\left.x_{3}\right)$ 相关标准完备性 & 0.09 \\
\hline 色 & & $\left(x_{4}\right)$ 规范合理性 & 0.07 \\
\hline 小 & & $\left(x_{5}\right)$ 政治生态的稳定性 & 0.06 \\
\hline 镇 & \multirow[t]{3}{*}{ 资金风险 $(J)$} & $\left(x_{6}\right)$ 投资经验 & 0.05 \\
\hline 建 & & $\left(x_{7}\right)$ 运营经验 & 0.02 \\
\hline 设 & & $\left(x_{8}\right)$ 资金是否充足 & 0.04 \\
\hline 风 & \multirow[t]{3}{*}{ 产业风险（C) } & $\left(x_{9}\right)$ 产业集中度 & 0.03 \\
\hline 险 & & $\left(x_{10}\right)$ 产业波动性 & 0.06 \\
\hline 评 & & $\left(x_{11}\right)$ 产业可持续性 & 0.06 \\
\hline 价 & \multirow[t]{5}{*}{ 运营风险（Y） } & $\left(x_{12}\right)$ 社会环境 & 0.04 \\
\hline 体 & & $\left(x_{13}\right)$ 市场环境 & 0.03 \\
\hline \multirow[t]{3}{*}{ 系 } & & $\left(x_{14}\right)$ 人才环境 & 0.05 \\
\hline & & $\left(x_{15}\right)$ 政策环境 & 0.07 \\
\hline & & $\left(x_{16}\right)$ 法律环境 & 0.08 \\
\hline
\end{tabular}

表 2. 特色小镇建设风险指标打分

\begin{tabular}{|c|c|c|c|c|c|}
\hline 因 子 & 类型 & 打分 & 因 子 & 类型 & 打分 \\
\hline \multirow[t]{3}{*}{ 合同是否正规 } & 是 & 1 & \multirow[t]{3}{*}{ 产业集中度 } & 高 & 1 \\
\hline & 一般 & 2 & & 中 & 2 \\
\hline & 否 & 3 & & 低 & 3 \\
\hline \multirow[t]{3}{*}{ 土地性质与用地需求是否匹配 } & 是 & 1 & \multirow[t]{3}{*}{ 产业波动性 } & 大 & 1 \\
\hline & 一般 & 2 & & 一般 & 2 \\
\hline & 否 & 3 & & 小 & 3 \\
\hline \multirow[t]{3}{*}{ 相关标准完备性 } & 是 & 1 & \multirow[t]{3}{*}{ 产业可持续性 } & 是 & 1 \\
\hline & 一般 & 2 & & 一般 & 2 \\
\hline & 否 & 3 & & 否 & 3 \\
\hline \multirow[t]{3}{*}{ 规范合理性 } & 是 & 1 & \multirow[t]{3}{*}{ 社会环境 } & 好 & 1 \\
\hline & 一般 & 2 & & 一般 & 2 \\
\hline & 否 & 3 & & 差 & 3 \\
\hline \multirow[t]{3}{*}{ 政治生态的稳定性 } & 是 & 1 & \multirow[t]{3}{*}{ 市场环境 } & 好 & 1 \\
\hline & 一般 & 2 & & 一般 & 2 \\
\hline & 否 & 3 & & 差 & 3 \\
\hline \multirow[t]{3}{*}{ 投资经验 } & 有 & 1 & \multirow[t]{3}{*}{ 人才环境 } & 好 & 1 \\
\hline & 一般 & 2 & & 一般 & 2 \\
\hline & 否 & 3 & & 差 & 3 \\
\hline \multirow[t]{3}{*}{ 运营经验 } & 有 & 1 & \multirow[t]{3}{*}{ 政策环境 } & 好 & 1 \\
\hline & 一般 & 2 & & 一般 & 2 \\
\hline & 否 & 3 & & 差 & 3 \\
\hline \multirow[t]{3}{*}{ 资金是否充足 } & 是 & 1 & \multirow[t]{3}{*}{ 法律环境 } & 好 & 1 \\
\hline & 一般 & 2 & & 一般 & 2 \\
\hline & 否 & 3 & & 差 & 3 \\
\hline
\end{tabular}

对应特色小镇建设风险评价等级低、中、高 三个等级。其中评价结果为高等级的, 表示
特色小镇建设风险较大，而中等风险次之， 低等风险表示特色小镇建设风险最低。 


\section{3. 风险评价模型构建}

针对多指标模型构建过程中难于选择 合适的评价模型, 而加权综合法可以依据 “先综合, 后对比” 的方式, 通过加权来测 定多种现象的综合变动状况, 准确的实现多 指标综合评价 [13-14]。结合特色小镇建设 风险评价过程及评价指标体系, 利用加权综 合评价法, 建立特色小镇建设风险评价评价 模型, 公式如下:

$T S=\sum_{i=1}^{n} w_{i} x_{i}$

$T S=\mathrm{w}_{T} T \times w_{Z} Z \times w_{J} J \times w_{C} C \times w_{Y} Y$

$T=w_{1} x_{T 1}+w_{2} x_{T 2}$

$Z=w_{1} x_{Z 1}+w_{2} x_{Z 2}+w_{3} x_{Z 3}$

$J=w_{1} x_{J 1}+w_{2} x_{J 2}+w_{3} x_{J 3}$

$C=w_{1} x_{C 1}+w_{2} x_{C 2}+w_{3} x_{C 3}$

$Y=w_{1} x_{Y 1}+w_{2} x_{Y 2}+w_{3} x_{Y 3}+w_{4} x_{Y 4}+$

$$
w_{5} x_{Y 5}
$$

式中: $\mathrm{TS}$ 为特色小镇建设风险评价指数, 用 来表示特色小镇建设风险大小, 其值越大, 特色小镇建设风险越大, 反之越小; T、Z、 J、C、Y 的值分别表示土地风险、政策风险、 资金风险、产业风险及运营风险五个因子; $\mathrm{x}_{\mathrm{i}}$ 是各指标量化后的值, $\mathrm{w}_{\mathrm{i}}$ 为各指标的权重 值。

\section{4. 结论与讨论}

风险评价是对特色小镇未来建设过程 中可能面临或潜在的风险加以判断、归类和 对风险性质进行鉴定的过程。将风险理论引 入到特色小镇建设研究中, 通过风险特征分 析、风险识别综合篮选了 5 个一级指标、 16 个二级指标, 并采用加权综合法构建特色小 镇建设风险评价模型。特色小镇建设风险评 价指标体系与模型的构建, 为其风险评价提 供简单、直观、可操作的思路与方法。

由于受资料与数据不完善的限制, 未能 实现特色小镇建设风险评价评估, 只是在文 中构建了其评价指标体系与模型。在今后的 研究工作中, 将进一步开展实地调查与相关 资料、数据搜集, 以具体研究区为案例, 实 现特色小镇建设风险评价评估, 为我国特色 小镇建设提供决策依据。

\section{Acknowledgements}

This research has been funded by the Jilin social science base project.

\section{致谢}

本研究得到了吉林省社科基地项目的资助。

\section{参考文献}

[1] 黄静晗, 路宁. 国内特色小镇研究综述: 进 展与展望.当代经济管理:1-6.

[2] 赵庆海. 国外特色小镇建设的经验与启 示.人文天下,2017(22):35-40.

[3] Moles P, Williams G. Privately funded infrastructure in the UK: participants' risk in the Skye Bridge project. Trans port Policy,1995,2(2):129-134.

[4] 马斌. 特色小镇: 浙江经济转型升级的大 战略.浙江社会科学,2016(3):39-42.

[5] 陈立旭. 论特色小镇建设的文化支撑. 中 共浙江省委党校学报,2016,32(5):14-20.

[6] 蔡健, 刘维超, 张凌. 智能模具特色小镇规 划编制探索.规划师,2016,32(7):128-132.

[7] 张鸿雁. 论特色小镇建设的理论与实践 创新.中国名城,2017(1):4-10.

[8] 史云贵.当前我国城市社区治理的现状、 问题与若干思考. 上海行政学院学 报,2013,14(2):88-97.

[9] 陈清, 吴祖卿.福建特色小镇发展建设的 “资源+人才+创新” 策略分析. 福建论 坛(人文社会科学版),2017(3):161-166.

[10] 王振坡,薛珂,张颖,等. 我国特色小镇发 展进路探析.学习与实践,2017(4):23-30.

[11] 赵佩佩, 丁元. 浙江省特色小镇创建及其 规划设计特点剖析. 规划 师,2016,32(12):57-62.

[12] 李鹏举, 崔大树. 空间交易费用、产权配 置与特色小镇空间组织模式构建--基于 浙江特色小镇的案例分析. 城市发展研 究,2017,24(6):10-17.

[13] Sun Y Y, Yang Q S, Chen P. A Study of Spatial Evolution Patterns of Tourist Destinations Disaster Risks. Journal of Risk Analysis and Crisis Response, 2018, 8(1): 35-42

[14] 乌兰. 草原雪灾社会影响评价指标体系 与概念模型. 中国灾害防御协会风险分 析专业委员会第六届年会论文 集.2014,5. 